\title{
Diagnóstico prenatal de iniencefalia. Reporte de caso
}

\author{
Duly Torres-Cepeda, ${ }^{1}$ (D) Eduardo Reyna-Villasmil, ${ }^{2}$ (D) Martha Rondon-Tapia. ${ }^{3}$
}

\begin{abstract}
RESUMEN
La iniencefalia es un defecto infrecuente y fatal del tubo neural que afecta al occipital y al cuello, esto ocurre junto con ensanchamiento del foramen magnum, raquisquisis y marcada retroflexión de la cabeza. Esta entidad pertenece al grupo de defectos del cierre del tubo neural. Cerca de 200 informes han sido publicados en la literatura. Se puede hacer el diagnóstico utilizando un examen de morfología por ultrasonido que es fácil de realizar debido a los hallazgos característicos de la condición. Las anomalías asociadas del sistema nervioso y otros sistemas están presentes con frecuencia durante la evaluación ecográfica. El diagnóstico prenatal de un defecto del tubo neural que involucra defectos del occipital y raquisquisis de la columna cervical - torácica acompañada de retroflexión de la cabeza debe plantear la sospecha diagnóstica de iniencefalia. El pronóstico es particularmente malo, con solo unos pocos casos de supervivencia.
\end{abstract}

Palabras clave: Iniencefalia, Defecto del tubo neural, Diagnóstico prenatal.

\section{Prenatal diagnosis of iniencephaly. Case report}

\section{SUMMARY}

Iniencephaly is an infrequent and fatal neural tube defect that affects the occiput and neck, this occurs together with the widening of the foramen magnum, rachischisis and marked retro-flexion of the head. This entity belongs to the group of defects of neural tube closure. About 200 reports have been published in the literature. A diagnosis can be made using an ultrasound morphology test that is easy to perform due to the characteristic findings of the condition. Associated anomalies of the nervous system and other systems are frequently present during the ultrasound evaluation. Prenatal diagnosis of a neural tube defect that involves occipital defects and spinal and thoracic spine rachischisis accompanied by retro-flexion of the head should raise the diagnostic suspicion of iniencephaly. The prognosis is particularly bad with only a few cases of survival.

Keywords: Iniencefalia, Neural tube defect, Prenatal diagnosis.

\section{INTRODUCCIÓN}

La iniencefalia es un defecto del tubo neural extremadamente raro cuyas características diagnósticas incluyen: ausencia de la porción escamosa del occipital acompañada de agrandamiento del foramen magnum,

\footnotetext{
${ }^{1}$ Doctora en Ciencias Médicas. Especialista en Ginecología y Obstetricia. ${ }^{2}$ Doctor en Medicina Clínica. Especialista en Ginecología y Obstetricia. ${ }^{3}$ Especialista en Ginecología y Obstetricia. Hospital Central "Dr. Urquinaona". Maracaibo. Estado Zulia. Venezuela.
}

Forma de citar este artículo: Torres-Cepeda D, Reyna-Villasmil E, RondónTapia M. Diagnóstico prenatal de iniencefalia. Reporte de caso. Rev Obstet Ginecol Venez. 2021; 81(3):287-291. https://doi.org/10.51288/00810312 ausencia parcial o total de vértebras cervicales torácicas o formas anatómicas rudimentarias de estas estructuras, raquisquisis, acompañada de espina bífida e hiperextensión de la columna cervicotorácica que conlleva a que la cara gire hacia arriba. Su nombre deriva de las palabras griegas inion (cuello) y cefalo (cabeza) (1). Se han descrito cerca de 200 casos de iniencefalia con etiología desconocida y posiblemente heterogénea $(1,2)$. El pronóstico es particularmente malo y la supervivencia es improbable. La ecografía prenatal permite diagnosticar la gravedad de las anomalías cervicooccipitales y su asociación con otras malformaciones (3). Se presenta un caso de diagnóstico prenatal de iniencefalia. 


\section{CASO CLÍNICO}

Se trata de una paciente de 20 años de edad, primigesta, con embarazo de 13 semanas quien fue referida de otro centro por presentar alteraciones en la ecografía del primer trimestre. La paciente negaba antecedentes personales o familiares de importancia, al igual que la exposición a agentes teratógenos (drogas o radiaciones) durante el embarazo. No existían lazos de consaguinidad con el cónyuge.

En el examen físico, el útero estaba aumentado de tamaño y correspondía con la edad gestacional. En la evaluación ecográfica, se observó un feto único vivo con líquido amniótico normal, hiperextensión de la cabeza y en posición relativamente fija, cuello corto, con fusión del occipucio a la columna vertebral (figura 1 y 2), alteración de los cuerpos vertebrales, cifoscoliosis grave, hiperextensión de los miembros inferiores y flexión marcada de los miembros superiores y ligero talipés equinovaro bilateral. No se encontraron otras anomalías asociadas. La amniocentesis mostró un cariotipo normal 46XX. En vista de todos estos hallazgos se realizó el diagnóstico de iniencefalia.

Durante la evaluación del control, a las 19 semanas, se observó ausencia de frecuencia cardiaca fetal y de movimientos fetales activos, por lo que se procedió a realizar maduración y dilatación del cuello uterino, con vaciamiento y posterior legrado uterino. Se obtuvo un feto muerto de 420 gramos. La cabeza estaba en retroflexión y el cuello en hiperextensión. La piel de la cara tenía continuidad con la del tórax. También se observó pie equino bilateral. No se observaron otras malformaciones asociadas en el examen necrológico. En vista de los hallazgos clínicos y de imágenes se realizó el diagnóstico de iniencefalia.

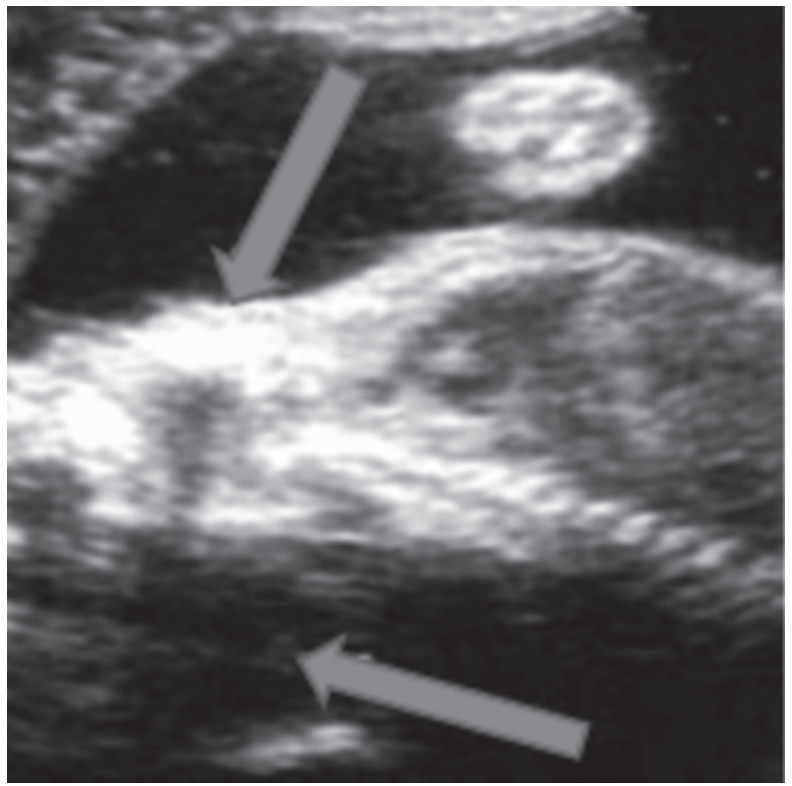

Figura 1. Ecografía del primer trimestre en la que se observa la porción anterior de la cabeza que continua con el cuello, con ausencia de protrusión normal de la mandíbula inferior (flecha superior), acompañado de retroflexión de la cabeza (flecha inferior).

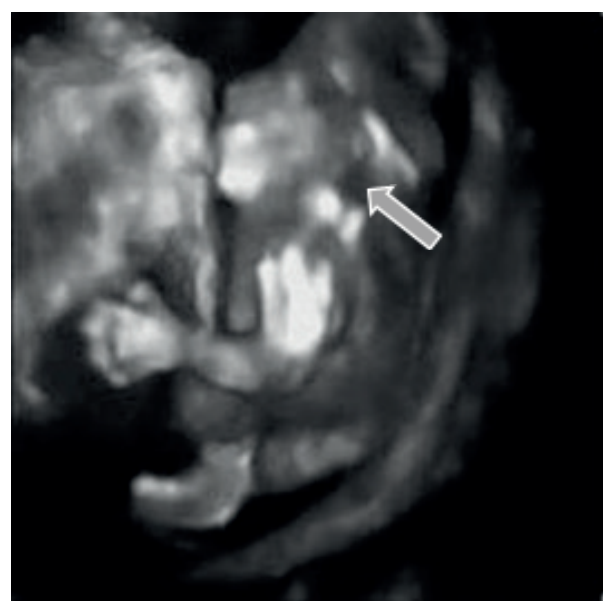

Figura 2. Reconstrucción tridimensional en la que se observa la retroflexión marcada de la cabeza característica de la iniencefalia. 


\section{DISCUSIÓN}

La iniencefalia es producto de la detención en retroflexión fisiológica del embrión en la tercera semana o del fracaso de la inclinación normal hacia delante durante la cuarta semana de gestación, previo al cierre del neuroporo cefálico (4). El cierre de este neuroporo es bidireccional y se sitúa en la futura placa comisural, en medio de la lámina terminal embrionaria. Los esclerotomas paravertebrales, de origen mesodérmico, se diferencian precozmente en una masa ventral (cuerpos vertebrales y pedículos) y otra masa dorsal (arcos posteriores y bóveda craneana) (5). La hipoplasia de las masas mesodérmicas ventrales y/o dorsales determinaría la malformación como un defecto complejo que permite la comunicación directa entre la fosa posterior craneal y la porción cervical del canal medular. La segmentación occipitocervical está bajo el control de la familia de genes homeobox. Las mutaciones en los genes Hox serían responsables de las anomalías del tubo neural y de los defectos mesodérmicos del occipucio y columna vertebral cervical alta (6). Diferentes factores ambientales como la sífilis materna y medicamentos como citrato de clomifeno, tetraciclinas y sedantes, se han postulado como factores etiológicos, pero no existen evidencias definitivas. La incidencia global es de 0,1 a 10 por 10000 neonatos, con preponderancia en fetos femeninos $(90 \%)$ (1). El riesgo de recurrencia en familias con antecedentes de defectos del tubo neural es cercano al $5 \%$ (7).

Las características principales de la iniencefalia incluyen: alteraciones variables del hueso occipital, que produce agrandamiento del foramen magnum, ausencia parcial o total de vértebras cervicales y torácicas, con fusión irregular de las vértebras presentes, acompañado de cierre incompleto de arcos y cuerpos vertebrales, hiperextensión de la columna cervicotorácica malformada, con acortamiento debido a lordosis, cara girada hacia arriba y piel mandibular continua con la del tórax debido al cuello corto (2, $3)$. Se ha clasificado en dos tipos según la presencia (apertus) o ausencia (clausus) de encefalocele $(8,9)$. También se ha clasificado como iniencefalia simple (apertus o clausus) e iniencefalia con anencefalia (anencefalia con retroflexión espinal) (3).

Las anomalías embriológicas asociadas que afectan al sistema nervioso central y otros sistemas se observan en el $75 \%$ de los casos. Puede asociarse con otras malformaciones como artrogriposis, anencefalia, holoprosencefalia, espina bífida, ausencia de mandíbula, paladar hendido, hipoplasia o hiperplasia pulmonar, hiperplasia cardiaca, gastrosquisis, atresia gastrointestinal, arteria umbilical única, anomalías renales, esplenomegalia gigante, ciclopía, genu recurvatum e hidramnios $(2,8,9)$.

Como en la detección de otras anomalías craneoespinales, la ecografía es la modalidad diagnóstica de elección para el diagnóstico prenatal de iniencefalia; se puede realizar desde el inicio, tan temprano como las 11 - 14 semanas, observándose flexión cefálica dorsal, anomalías vertebrales o de la columna cervical y polihidramnios, debido a la dificultad del feto para deglutir líquido amniótico (2). Se recomienda realizar evaluación ecográfica extensa en busca de ausencia de los parietales o tejido cerebral, polo cefálico por detrás y encima de los hombros, ausencia de las estructuras normales del cuello, raquisquisis y mielomeningocele, para confirmar o descartar el diagnóstico $(1,9)$.

En caso de encontrarse alguna dificultad diagnóstica, la resonancia magnética es una técnica eficaz para evaluar los hallazgos ecográficos fetales, ya que no expone al paciente a la radiación ionizante. El sistema nervioso central y otras estructuras anatómicas del feto se visualizan por resonancia magnética desde el comienzo del segundo trimestre, por lo que los hallazgos ecográficos se pueden confirmar en la 
mayoría de los casos y se puede obtener información adicional sobre el diagnóstico, gravedad y ubicación precisa de las anomalías (10). Las concentraciones de alfafetoproteína en suero materno, método de cribado más importante para detectar defectos del tubo neural, pueden estar elevadas (11). Es conveniente la realización de cariotipo con bandas $\mathrm{G}$ de alta resolución de muestra de biopsia de vellosidad coriónica, amniocentesis, cordocentesis o en el feto, para descartar alteraciones cromosómicas numéricas o estructurales (2).

La iniencefalia exhibe características similares al síndrome de Kippel-Feil que se caracteriza por brevedad del cuello (brevicollis congénito), secundario a la fusión de las vértebras cervicales y, eventualmente, las vértebras torácicas altas, deformación del raquis (cifosis o escoliosis) y retroversión de la cara que se debe a alteraciones en la segmentación de las vértebras cervicales. También se asocia con sordera, defectos cardiacos congénitos y retraso mental, entre otras anomalías. Rara vez es letal y, a menudo, se puede corregir quirúrgicamente. Se produce en alrededor de 1 de cada 42000 nacimientos y en el $65 \%$ son del sexo femenino (12). Esta anomalía se considera un defecto de segmentación. Un desarrollo alterado de las zonas mesenquimatosas densas y menos densas alrededor de las 5 semanas de gestación daría lugar a un tipo de fusión vertebral, aunque también se ha propuesto un origen posterior. Asimismo, se han sugerido defectos notocordales $(1,12)$. El otro diagnóstico diferencial es la disostosis espondilocostal o síndrome de JarchoLevin, caracterizada por un tronco corto y múltiples anomalías vertebrales y costales que pueden asociarse con otros defectos mortales. En ambas condiciones, se deberealizar asesoría genética, porque existen informes de casos con patrones de herencia mendelianos (12).

La mayoría de los embarazos se interrumpen de forma espontánea y prematura. En casos raros llegan al término con la obtención de un feto muerto o que sobrevive horas o días, ya que se asocia con anomalías cardiacas, hernia diafragmática, atresia intestinal, defectos renales, entre otras, lo que la convierte en una condición generalmente fatal (1). Sin embargo, existen informes de ocho casos de pacientes con afecciones leves que han sobrevivido, con edades comprendidas entre los dos meses y los 17 años (2).

En conclusión, la iniencefalia es un defecto del tubo neural de muy baja prevalencia y letal, que se caracteriza por la presencia de un defecto en el componente óseo occipital, raquisquisis cervical o torácica y retroflexión de la cabeza. Las mutaciones en la familia de genes homeobox podrían ser el origen de esta malformación. El diagnóstico ecográfico prenatal es posible desde las 11 -14 semanas. El pronóstico fetal es malo con una alta mortalidad.

\section{REFERENCIAS}

1. Chen CP. Prenatal diagnosis of iniencephaly. Taiwan J Obstet Gynecol. 2007; 46(3):199-208. doi: 10.1016/ S1028-4559(08)60021-2.

2. Alvis-Miranda HR, Bula-Anichiarico DA, CalderónMiranda WG, Moscote-Salazar LR. Iniencephaly: Case Report. J Pediatr Neurosci. 2015; 10(2):181-184. doi: 10.4103/1817-1745.159211.

3. Kulkarni PR, Rao RV, Alur MB, Joshi SK. Iniencephaly clausus: A case report with review of literature. J Pediatr Neurosci. 2011; 6(2):121-123. doi: 10.4103/18171745.92831.

4. Glenn OA, Coakley FV. MRI of the fetal central nervous system and body. Clin Perinatol. 2009; 36(2):273-300, viii. doi: 10.1016/j.clp.2009.03.016.

5. Diaz Primera R, Gil Guevara E, González Arias F, Bermúdez González C. Iniencephaly Apertus: Prenatal Autopsy by Sonography and Embryoscopy. J Ultrasound Med. 2017; 36(10):2188-2189. doi: 10.1002/jum.14279.

6. Parker HJ, Bronner ME, Krumlauf R. A Hox regulatory network of hindbrain segmentation is conserved to the base of vertebrates. Nature. 2014; 514(7523):490-493. doi: 10.1038/nature13723. 
7. Pollazzon M, Rosato S, Ivanovski I, Gelmini C, Bertani G, Pascarella R, et al. Complex cranio-vertebral malformation: disruption sequence or iniencephaly? Clin Dysmorphol. 2018; 27(3):105-108. doi: 10.1097/ MCD.0000000000000218.

8. Gutiérrez A, Guerrero B, Araujo L, Giugni A, Rivas A, Henríquez M. Iniencefalia apertus, asociación con agenesia cerebelosa y pulmonar: a propósito de un caso. Gac Med Caracas. 1999; 107(3):358-360.

9. Bermúdez A, Sosa Olavarría A, Rivas M, Miraz M. Iniencefalia: serie de seis casos. Rev Obstet Ginecol Venez. 1995; 55(3):161-165.

10. Balci S, Aypar E, Altinok G, Boduroğlu K, Beksaç MS. Prenatal diagnosis in three cases of iniencephaly with unusual postmortem findings. Prenat Diagn. 2001; 21(7):558-562. doi: 10.1002/pd.97.
11. Demir MK, Çolak A, Ekşi MŞ, Özcan-Ekşi EE, Akakın A, Yilmaz B. Atretic cephaloceles: a comprehensive analysis of historical cohort. Childs Nerv Syst. 2016; 32(12):2327-2337. doi: 10.1007/s00381-016-3194-z.

12. Karaca L, Sade R, Kantarci M, Yüce I, Ogul H, Bayraktutan U. Klippel-Feil syndrome with butterfly vertebrae: rare case. Spine J. 2016; 16(11):e729-e730. doi: 10.1016/j.spinee.2016.03.028.

Recibido 19 de octubre de 2020 Aprobado 20 de enero de 2021 